Cad.Est.Ling., Campinas, 48(2):263-282, 2006

\title{
LEITURA E ESCRITA NA AUSÊNCIA DA FALA
}

\author{
CELINA MARIA RAMOS A. MACEDO \\ Universidade Federal de Santa Catarina
}

\begin{abstract}
TH is tetraplegic and speech impaired. Although some studies show the dificulties that individuals with brain palsy and anarthria demonstrate when they developed literacy abilities, the experiments results suggest that $\mathrm{TH}$ presents reading, writing and oral compreension abilities.
\end{abstract}

Keywords: Tetraplegic, anarthria, literacy.

\section{INTRODUÇÃO}

TH é um aluno de uma escola pública de Florianópolis portador de tetraplesia e com comprometimento na fala, ou seja, TH nunca articulou palavras. Nesta pesquisa experimental, decidiu-se trabalhar com o sujeito TH em razão de que crianças portadoras de anomalias severas na produção da fala mostram não desenvolver um conhecimento apropriado das estruturas das palavras. Assim, segundo Dodd, Leahy e Hambly (1989) essas crianças não distinguem entre pseudopalavras fonologicamente legais e ilegais. Não tendo desenvolvido competências morfofonêmicas, pode-se esperar que elas também tenham dificuldade para aquisição do conhecimento das regras de correspondência grafo-fonológica mais complexas e, em particular, das grafias que dependem da morfologia. Além disto, um trabalho de Bishop e Robson (1989) mostra que as crianças anártricas apresentam uma clara inferioridade na escrita de palavras e de pseudopalavras quando se comparadas a crianças com enfermidade motora, mas com fala normal. Pareceu-nos, portanto, que TH constitui um caso interessante nesta perspectiva, dado que ele nunca falou e, no entanto, parece apresentar um desenvolvimento cognitivo normal, como o sugere, seus resultados escolares. Observa-se, também, que TH está adquirindo normalmente uma língua estrangeira, o francês, quer na sua habilidade de compreensão quer na sua habilidade de expressão.

Neste estudo, tentou-se colocar em evidência não só as estratégias utilizadas pelo sujeito TH no processamento da escrita e da leitura, mas também avaliar sua consciência metafonológica. Discutiu-se ainda, se e como o comprometimento motor, falta de fala, e o conhecimento metafonológico foram associados às habilidades de letramento de $\mathrm{TH}$. Portanto, o objetivo desta pesquisa é a análise de letramento e a análise das habilidades metafonológicas do sujeito TH em comparação a um grupo controle formado por 14 adolescentes falantes que estudavam na mesma série e escola do que TH. 


\section{PRESSUPOSTOS TEÓRICOS}

Crianças anártricas conhecem a leitura e a escrita com diferentes pré-requisitos daqueles das crianças que falam. Muito antes das crianças falantes serem alfabetizadas, elas já conhecem várias palavras, compreendem e produzem a linguagem oral. Logo, possuem representações fonológicas baseadas em palavras e significados correspondentes, bem como um sistema de análise gramatical eficiente à compreensão e produção da fala. Isto, provavelmente, não ocorre da mesma forma com as crianças não falantes.

Embora algumas pessoas não falantes aprendam a ler, alguns estudos evidenciam as dificuldades que as pessoas não falantes com paralisia cerebral demonstraram quando adquiriam habilidades de letramento (BERNINGER \& GANS, 1986a, B; D.V.M. BISHOP \& ROBSON, 1989; KELFORD, THURSTON, LIGHT, PARNES \& O'KEEFE 1989; MCGINNIS \& BEUKELMAN, 1989, SMITH 1989, 1992, KOPPENHAVER, EVANS \& YODER, 1991; FOLEY, 1993). A paralisia cerebral severa é uma disfunção, que atinge tanto a função motora grossa quanto a função motora fina. Outrossim, os indivíduos são anártricos (apresentam a impossibilidade de articular as palavras, embora não haja paralisia dos músculos da fonação) ou severamente disártricos (apresentam dificuldades na articulação das palavras, resultante de perturbação nos centros nervosos). Portanto, alguns problemas de letramento poderiam ser esperados nesta população. Os estudos de D.V.M. Bishop \& Robson, 1989 e de Edebol-Tysk, 1989 demonstraram que o comprometimento cerebral entre pessoas não falantes poderiam ser associados à diminuição do nível intelectual. Mais tarde, os estudos de D.V.M. Bishop \& Adams, 1990 e Snowling, 1991 demonstraram que leitura e soletração estão relacionados ao funcionamento intelectual na população falante.

De acordo com Morais (1998), aprender a ler e escrever consiste em associar uma forma ortográfica à sua forma fonológica. Estudos demonstram que mesmo em sujeitos falantes existem diferenças individuais na aprendizagem da leitura as quais podem estar relacionadas à inferioridade nas capacidades gerais de compreensão, desarmonia nas capacidades específicas de leitura, dificuldades sócio-econômicas, cognitivas, sensoriais, perceptivas, lingüísticas e anomalias genéticas. A origem das dificuldades ou disfunções na aprendizagem da leitura pode ser encontrada, em última análise, ao nível dos fatores biológicos ou do meio ambiente, eventualmente na interação destes dois fatores. Tais fatores não afetam diretamente a performance, mas através do nível mental, os processos mentais. No entanto, percebe-se que crianças que lêem mais, desenvolvem melhor as suas bases de conhecimento. As capacidades cognitivas, capacidades associadas à descodificação grafofonológica e às capacidades de compreensão de texto são resultantes de duas outras capacidades: capacidade de identificação de palavras e capacidade de compreensão da fala. Corroborando com esta idéia, Alégria et al. (1997) garante que os processos de identificação de palavras embora sejam necessários à compreensão na leitura, não são suficientes por si só, porque não são processos de compreensão.

Philip Gough (1986) afirma que a leitura é formada pela descodificação grafofonológica e a compreensão da linguagem falada. Conseqüentemente, a leitura é o produto da performance de descodificação e da compreensão oral de um texto. Logo, nem a descodificação com ausência de compreensão e nem a compreensão com ausência de 
Cadernos de Estudos Lingüísticos 48(2) - Jul./Dez. 2006

descodificação levam à leitura. A partir daí pode-se inferir que crianças com deficiência ou na compreensão da língua oral ou na identificação de palavras, em fases iniciais de leitura, apresentam uma má compreensão da língua escrita. Ao contrário, quando a compreensão da língua escrita é boa, a compreensão da língua oral e a identificação de palavras são, provavelmente, boas.

Morais (1998) atesta que os bons leitores, normalmente, lêem mais que os maus leitores e por isso têm mais ocasião de encontrar não só estratégias de tratamento da informação, mas também de organizar na memória as estruturas do texto em relação ao mundo real e de suas referências temáticas. Morais lembra de que os processos de desenvolvimento compreendem os fatores motivadores e afetivos. A quantidade de leitura, o nível de compreensão e o nível de satisfação, ao contrário da insatisfação experimentada por crianças e seus pais, reforçam mutuamente em um sentido positivo ou negativo.

Infere-se, então, que não só o contexto cultural e social afetam o modo pelo qual adquire-se e utiliza-se a linguagem, mas também o contexto cognitivo. Isto é, o que se pode dizer, ler, escrever e entender depende, também, do que se sabe e como se organiza o que se sabe.

Logo, crianças com comprometimento motor decerto conhecem a leitura e a escrita com diferentes pré-requisitos daquelas que falam. O dano motor limita o contato destas crianças com o mundo à sua volta. Estas crianças, normalmente, não conseguem manusear objetos, recebem informações limitadas e, conseqüentemente, apresentam vocabulário limitado. Além do mais, o comprometimento da fala limita a comunicação funcional e provavelmente acarreta problemas ao nível metalingüístico. No estudo de caso com crianças com a fala severamente prejudicada, Roth \& Cassat- James (1989) acharam que a compreensão verbal estava claramente acima das habilidades expressivas, mas não intactas. As crianças com a fala severamente prejudicada eram boas para compreender palavras, mas eram mais fracas para compreender sentenças. De acordo com D.V.M. Bishop, Byers Brown \& Robson (1990) as crianças anártricas portadoras de paralisia cerebral apresentavam um vocabulário receptivo prejudicado. No estudo de D. V.M. Bishop \& Adams (1990), comprovou-se que a competência lingüística e às habilidades de linguagem são relacionadas às habilidades de letramento na população falante. Em 1994, Rankin, Harwood \& Miranda revisaram estudos sobre a relação entre conhecimento de palavras, conhecimento sintático e leitura. Eles encontraram índices de que as habilidades da leitura estariam relacionadas às habilidades de linguagem. Stanovich (1986) argumentou que o conhecimento de mundo ou o uso do contexto poderia aumentar a eficiência de leitura, tanto para o reconhecimento de palavras como para o processo de compreensão. O estudo feito por Smith (1992) em crianças não falantes com paralisia cerebral demonstra que essas crianças compreendem o vocabulário receptivo, mas ainda não têm a habilidade de leitura. Assim, Smith (1992) afirma que somente linguagem receptiva não poderia explicar a realização de leitura. Berninger \& Gans (1986a) argumentaram que por causa do dano motor, a criança não falante com paralisia cerebral precisaria de um treinamento especial para o desenvolvimento de habilidades, tais como: análise de padrão de som, conhecimento de vocabulário, compreensão de sintaxe e discurso habilidades que estão, possivelmente, relacionadas a um bom desenvolvimento de letramento entre crianças falantes. De qualquer forma, segundo 
MACEDO - Leitura e escrita na ausência da fala

Alegria (1985) todas as crianças falantes adquirem a linguagem oral de maneira espontânea, sem a intervenção de instituições socialmente organizadas ao contrário da leitura que precisa ser adquirida.

Caso interessante e com resultados contrários aos estudos acima citados foi o de Richard Boydell estudado por Foucin, A.J., em 1962. Richard, apesar de ser um sujeito quadriplégico congênito, anártrico e com perda de audição de alta frequiência, apresentava boa compreensão da língua oral, lia e escrevia.

A importância da produção da fala para o desenvolvimento do letramento se relaciona à questão do conhecimento fonológico. Este é um dos indicadores estabelecidos na população falante, para o desenvolvimento da habilidade de letramento (LUNDBERG 1989, 1991; HOIEN \& LUNDBERG, 1992).

As habilidades fonológicas estão, geralmente, relacionadas à aquisição de leitura. Estas habilidades se referem à sensibilidade para fazer uso de fonemas da língua oral. Poucos não são os estudos sobre este tema (BERTELSON, 1987; MORAIS, ALEGRIA \& CONTENT, 1987; GOSWAMI \& BRYANT, 1990; WAGNER \& TORGESEN, 1987; MANN \& DITUNNO, 1990). Alguns estudos demonstram que o progresso na aquisição da leitura está ligado ao desenvolvimento das habilidades metafonológicas (GATHERCOLE, WILLIS \& BADDELEY, 1991; WAGNER, TORGESEN \& RASHOTTE, 1994; BAST, 1995; NÄSLUND \& SCHNEIDER, 1996; WAGNER et al. 1997). Vários estudos evidenciam que o treinamento das habilidades fonológicas, antes do início da alfabetização, favorece a aquisição de leitura (LUNDBERG et al., 1988; BYRNE \& FIELDINGBARNSLEY, 1993, 1995). Certos estudos demonstram que a falta de habilidade de leitura tem sido encontrada junto com déficit fonológicos (BRUCK, 19920). Outros estudos demostram que a falta de conhecimento fonológico em pessoas não falantes dificulta a atividade de letramento (BERNINGER \& GANS 1986 A; SMITH, 1989, DAHLGREN SANDBERG \& HJELMQUIST, E., 1996; DAHLGREN SANDBERG \& HJELMQUIST, E., 1996; FOLEY, 1993). Estudos demonstram que o efeito de retroalimentação auditória pode auxiliar na habilidade de descodificação (KOKE \& NEILSON, 1987; FOLEY, 1993).

Conforme Morais, Kolinsky e Mousty (1998) a consciência fonêmica começa a se desenvolver quando e porque as crianças têm que aprender o que as letras representam. Hipótese semelhante coloca Abaurre (1998) quando afirma que as crianças antes de entrarem em contato com a escrita alfabética não analisam ainda as sílabas em segmentos.

Estudos sobre crianças pré-escolares não falantes, não retardadas, que ainda não estão recebendo treinamento de letramento formal indicam que estas crianças apresentam dificuldades com alguns dos indicadores de conhecimento fonológico, a saber, síntese de fonemas e análise de comprimento de palavras. Já o reconhecimento de rima foi a tarefa mais fácil tanto para as crianças problemáticas quanto para as crianças falantes do grupo de comparação (DAHLGREN SANDBERG \& HJELMQUIST, E., 1996).

Os estudos de Wimmer et al. (1991) demonstram que crianças falantes não leitoras não possuem consciência fonológica em nível de fonema. De forma similar, os estudos de Morais et al. (1987) revelam que a consciência fonológica em nível de fonema desenvolvese em conjunto com a aprendizagem da leitura ou de sua decorrência. Mais tarde, Morais, Mousty \& Kolinsky (1998) endossam a questão de 1987 quando afirmam que a relação 
Cadernos de Estudos Lingüísticos 48(2) - Jul./Dez. 2006

entre aquisição da consciência sobre o fonema e a aquisição do letramento alfabético é a de causalidade recíproca. Também, os estudos realizados por Goldstein, 1976; Ellis, 1990; Brady et al., 1994 mostraram que a consciência fonológica e a memória são influenciadas pela aprendizagem da leitura.

Portanto, tem sido dada grande ênfase à consciência fonológica para explicar a aprendizagem dos sistemas alfabéticos pelas crianças. Segundo Mattingly (1972:133) "a leitura é um tipo de atividade secundária que depende de forma crucial da consciência que o leitor tem de suas atividades primárias, no caso a fala".

As crianças antes de serem alfabetizadas percebem a cadeia da fala como um contínuo sendo esta uma das razões pelas quais elas apresentam dificuldades em relacionar os grafemas aos fonemas. No momento em que as crianças começam a ser alfabetizadas, elas têm que passar a perceber a cadeia da fala não mais como um contínuo, têm que desmembrar essa cadeia da fala em partes menores que a sílaba e têm que internalizar regras de correspondência, a maior parte das quais não biunívocas. Scliar-Cabral (2003) afirma que é importante observar "as propriedades do continuиm da cadeia da fala, em que está implicado o fenômeno da coarticulação, oposto ao caráter discreto das unidades da escrita, em especial, da escrita alfabética". Portanto, para poder estabelecer as correspondências grafo-fonológicas, as crianças precisam adquirir a consciência do fonema. Nakamura, Kolinsky, Spagnoletti \& Morais, (1998:423) afirmam que "a capacidade para a segmentação fonêmica consciente é um componente crucial para aprender a ler em nosso sistema".

A questão é se as crianças que não falam adquirem a consciência fonológica. Pesquisas têm fornecido evidências de tais conhecimentos fonológicos em população de anártrico ou severamente disártrico, embora a consciência fonológica não esteja sempre intacta (BADDELEY \& WILSON, 1985; D.V.M. BISHOP, 1985; D.V.M. BISHOP, BYERES BROWN \& ROBSON, 1990; D.V.M. \& ROBSON, 1989; DAHLGREN SANDBERG \& HJELMQUIST, E., 1996; FOLEY, 1993). Existem indicações de que crianças que não falam, apresentam problemas com a representação de sons de palavras especialmente se as palavras forem representadas somente por objeto e não por fala (DAHLGREN SANDBERG \& HJELMQUIST, E., 1996). Tais problemas poderiam levar a dificuldades para construções estáveis de representações fonológicas na memória (GATHERCOLE \& BADDELEY, 1990).

Crianças não falantes com paralisia cerebral severa usam, normalmente, 2 sistemas para a comunicação: linguagem falada receptivamente e BLISS expressivamente. A produção BLISS é freqüentemente de caráter telegráfico. BLISS é um sistema representacional gráfico onde palavras e partes de palavras são representadas por signos arbitrários (HEHNER, 1982). A representação acontece em um morfema ou em nível de palavra. Para os não falantes, a aquisição de um modo de expressão é fundamental para que eles possam compartilhar os seus conhecimentos de mundo. Segundo Sandberg e Hjelmquist (1997), crianças não falantes aprendem a manusear meios não alfabéticos para expressar as suas idéias e experiências. Elas aprendem que o mesmo conteúdo pode ser expresso em diferentes formas, oralmente e graficamente, o que é importante no desenvolvimento da leitura (OLSON 1982; HEDELIN \& HJELMQUIST, 1988). Não há nada inerente nos símbolos BLISS que possa levar a criança ao uso de um princípio 
MACEDO - Leitura e escrita na ausência da fala

alfabético para o código impresso, o qual é necessário para uma leitura e soletração eficientes.

No estudo feito por Kelford, S. et al. (1989), pessoas que usaram o sistema BLISS mostraram dificuldade em escrever corretamente. Isto pode ser um problema de linguagem básica ou uma conseqüência do uso do sistema BLISS. Pois, existem limitações no sistema BLISS, por exemplo, o tamanho e a escolha de vocabulário, que podem restringir a elaboração de novos conceitos. Além do mais, o sistema BLISS tem um conjunto de regras para a combinação de símbolos nas sentenças e uma representação morfêmica que são diferentes do sistema alfabético. Portanto, o uso do BLISS pode, assim, ser somado às dificuldades de letramento encontradas em crianças não falantes com paralisia cerebral.

O enfoque da Conferência de Belmont (1971) centrou no caráter complexo dos princípios que subjazem os sistemas alfabéticos, sugerindo paradigmas experimentais. Assim sendo, desde então, muitos pesquisadores já enfatizaram a forma como as crianças apreendem o caráter complexo do sistema alfabético, é o que se vê, por exemplo, no trabalho pioneiro realizado por Weir e Venezki (1968), que estabelecem a importância das regras morfofonêmicas. Menciona-se, também, o trabalho de Morais, Alegria e Content (1987) que afirma que para desenvolver as habilidades de recodificação fonológica, os leitores principiantes devem estar aptos para descobrir como os fonemas se relacionam aos grafemas.

\section{O SUJEITO TH}

TH nasceu em 05/06/85, de parto normal com Fórceps, teve Anoxia que lhe causou seqüelas motoras graves (tetraplesia). Teve também comprometimento na fala.

TH vem sendo acompanhado por neurologistas desde a maternidade e a partir dos três meses de idade vem sendo tratado pelo método evolutivo Bobath, por um terapeuta ocupacional e por uma fonaudióloga. Apesar do tratamento que vem recebendo, TH apresenta dificuldades, não fala, não senta sozinho, a cabeça apesar de cair para trás apresenta elevação voluntariamente até a linha mediana, acompanha objetos com os olhos, apresenta retração de ombros, consegue com muita dificuldade levar as mãos (movimento não voluntário), a sua locomoção é no chão onde rola e se arrasta. No entanto, os profissionais que acompanham TH acreditam que ele tenha a parte cognitiva intacta e em funcionamento normal.

A procura de recursos para proporcionar e facilitar as condições de vida de TH, de forma que ele fosse capaz de trabalhar e de desenvolver suas aptidões, e a procura de tratamentos alternativos que acelerassem suas aquisições motoras, levaram os pais de $\mathrm{TH}$ a entrarem em contato no Canadá com Hugh Macmiliam Reabilitation Center, onde conseguiram o método BLISS para comunicação através de símbolos.

Na procura de proporcionar um melhor desenvolvimento cognitivo, social e cultural de $\mathrm{TH}$, fez com que seus pais procurassem uma escola da rede normal, onde ele pudesse ser alfabetizado e seguir seus estudos.

Em 1992, TH entrou, pela primeira vez, numa escola pública para cursar a primeira série. Ali permaneceu somente, por seis meses. Os professores achavam "muito difícil" lidar com TH. Além do mais, afirmavam que TH não conseguia aprender. 
Em 1993, por sorteio, TH entrou e permaneceu até o final do ensino médio numa escola pública experimental. Um dos cuidados dos pedagogos da escola foi com o vínculo de TH à sua família. Como eles eram? A partir dos primeiros contatos, percebeu-se que TH era um menino dócil, de fácil relacionamento, tranqüilo e paciente. Já sua família era bastante receptiva e dava todo apoio necessário a TH, inclusive estando presente na sala de aula. Pois, TH precisa da mediação de outra pessoa para se comunicar.

Uma das dificuldades dos professores foi introduzir TH junto a seus colegas de classe. Para isto, o grupo de colegas de TH era incentivado a querer compreendê-lo. Nas séries iniciais, normalmente, os alunos sentavam em pequenos grupos. E era colocado o desafio aos colegas dos pequenos grupos a interagirem com TH. Com o tempo, TH passou a participar das atividades normais da aula, em grupo ou individualmente, e a sua fórmula básica de comunicação é sim/não representada por um gesto elementar com a cabeça para frente ou para os lados. Por essa razão, para se comunicar com TH, é importante fazer perguntas que sugiram as respostas sim ou não.

TH foi exposto à alfabetização. Para ele o alfabeto era móvel. Cada letra tinha um imã onde o mediador ia perguntando letra por letra e ele ia respondendo sim ou não e as letras iam sendo colocadas lado a lado. Aos poucos TH começou a escrever palavras e frases. Da mesma forma, com a ajuda de um material móvel, TH aprendeu a fazer contas. Sempre uma pessoa montava as equações, mostrava os números e ele ia respondendo sim ou não. Mas, no final das atividades - não importava quais fossem - persistia a dúvida sobre a interferência da pessoa que o acompanhava. Será que essa pessoa entendeu todos os seus sinais? Teria essa pessoa conseguido não emitir opiniões próprias junto com as respostas de $\mathrm{TH}$ ?

O que se testemunhava enquanto TH estava na escola é que ele participava de algumas atividades de educação física, no colo da mãe ou de algum colega; participava das aulas de língua estrangeira - francês - das atividades escritas e das brincadeiras; participava das aulas de geografia, história, português e matemática dando a sua opinião. De que forma? A pessoa, que o intermediava, deduzia o assunto sobre o qual ele queria se pronunciar. Normalmente TH dava pistas olhando para algum lugar com fixação. Por exemplo, se o olhar de TH se fixava em uma página do livro e se houvesse, nesta página, uma imagem de um cachorro e TH olhasse incessantemente para o colega vizinho e para a imagem do cachorro, o intermediário perguntaria: "você quer saber se ele tem um cachorro?"; "você quer saber se ele lembra do teu cachorro?"; "você quer saber se ele gosta de cachorro?" e as questões iriam recebendo respostas "sim" ou "não" até o momento em que TH se sentisse satisfeito ou desistisse de dar opinião ou se passasse à forma escrita da questão.

$\mathrm{Na}$ parte escrita, a pessoa, que o intermediasse, mostraria cada letra do alfabeto e, com bastante paciência, formaria as palavras desejadas por TH. Já, quando TH ficava agitado na sua cadeira de rodas se pensava, com freqüência, em dois motivos: ou estaria insatisfeito com alguma coisa ou feliz e, por isso, gritava.

Os professores, os colegas e os funcionários, com o decorrer do tempo, foram percebendo que seria possível se comunicar com TH por meio de perguntas que possibilitassem respostas do tipo sim/não. As respostas de TH eram um dos meios de avaliação para que ele pudesse freqüentar a série seguinte. TH, também, tinha o 
MACEDO - Leitura e escrita na ausência da fala

acompanhamento de uma psicopedagoga. Ainda assim, permanecia a questão de se saber "até que ponto o mediador intervinha nas respostas de TH?"; como provar que TH realmente tem conhecimentos relativos às matérias ensinadas; como provar que ele pôde compreender e ter idéias próprias; como provar que ele se lembra, que ele julga o que lhe foi ensinado; como provar que ele escreve e lê?

Aqui está a oportunidade de demonstrar as habilidades de leitura e escrita de TH, maneiras pelas quais TH expressa o seu conhecimento de mundo.

Atualmente, TH cursa Agronomia na Universidade Federal de Santa Catarina.

\section{METODOLOGIA}

\subsection{Sujeitos}

Esta pesquisa foi feita com TH, um adolescente de 15 anos de idade, anártrico e portador de tetraplesia e um grupo controle formado por 14 sujeitos falantes, sendo 9 do sexo feminino e 5 do sexo masculino. Com idade cronológica média de 13 anos. Todos os sujeitos do grupo controle freqüentavam a mesma escola pública e série que TH.

\subsection{Procedimentos}

Em todos os testes experimentais, os sujeitos foram informados de que os itens seriam ouvidos através de um aparelho de som - fita cassete (não só para padronizar as questões, mas também para evitar qualquer tipo de interferência do pesquisador nas respostas dos sujeitos) e, também, de que suas respostas deveriam ser registradas em uma ficha. No caso de $\mathrm{TH}$, o experimentador registrava as suas resposta. $\mathrm{O}$ tempo dado para cada resposta foi de 3 segundos. Antes do início de cada experimento o pesquisador não só dava instruções da tarefa, mas também demonstrava e construía com os sujeitos um exemplo de como eles deveriam proceder durante a experiência. Os testes foram feitos em sessões coletivas com o grupo controle e individuais com $\mathrm{TH}$.

Para se saber a resposta de TH foi criado o seguinte código: quando TH olhava firmemente para o pesquisador, no momento em que o pesquisador apontava para um ítens - significava que aquele ítem era o ítem correto para TH.

\subsection{Testes}

Em 1998, Mousty, Leybaert, Alégria, Content \& Morais, equipe do Laboratório de Psicologia Experimental de Bruxelas, elaboraram testes para não só analisar os mecanismos cognitivos, mas também para auxiliar no diagnóstico clínico de crianças, na faixa etária de 7 a 12 anos, as competências que sustentam as habilidades de leitura e escrita. Estes testes foram chamados de BELEC (batterie d'évaluation du langage écrit et de ses troubles".

Nesta pesquisa, alguns dos testes que avaliam as capacidades metafonológicas e os testes de leitura e escrita da bateria BELEC foram adaptados para a língua portuguesa. 
Cadernos de Estudos Lingüísticos 48(2) - Jul./Dez. 2006

Houve adequação ao sistema fonológico do português do Brasil. Pois, aplicar em TH um teste de leitura e escrita - simplesmente pedir para ele ler ou escrever um parágrafo - não poderia detectar se ele tem um bom ou mau desempenho na leitura, já que TH apresenta comprometimento motor e não se expressa oralmente.

Todos os testes foram selecionados com o objetivo de não somente colocar em evidência as habilidades de leitura e escrita de TH, mas também observar, analisar e avaliar se TH adquiriu consciência fonológica.

Esta pesquisa foi dividida em dois experimentos. O primeiro experimento consistiu de três testes, a saber: leitura de palavras, leitura de pseudopalavras, escrita de palavras. O segundo experimento consistiu de três testes: a saber, descriminação perceptiva, acrônimos auditivos e capacidades metafonológicas (tarefa de inversão). Fez parte também destes testes a anamnese.

\subsubsection{Anamnese}

A anamnese se constitui de questões sobre o histórico das condições pré e peri natais de $\mathrm{TH}$, principais etapas do seu desenvolvimento motor, doenças ou internações significativas, aspectos do seu comportamento social bem como aspectos do seu desenvolvimento intelectual.

\section{Experimento 1}

Avaliação das habilidades de leitura e ortografia

\section{A. Testes de leitura de palavras}

Para analisar as estratégias utilizadas pelo sujeito TH no domínio da ortografia da língua portuguesa, se fez uso do teste de discriminação de palavras escritas, onde se elaborou uma lista de 12 pares de palavras que diferiam apenas pela consoante inicial. O sujeito ouvindo o ítem alvo, deveria fazer a escolha deste mesmo item entre dois itens apresentados. Por exemplo: entre as palavras Cola e Bola o item alvo era Bola. Então, o sujeito deveria marcar na folha resposta Bola. No caso de TH, o experimentador mostrava a palavra Cola, perguntando: "foi essa palavra que eu ditei?" e depois mostrava a palavra Bola, perguntando: "foi essa palavra que eu ditei?" quando TH olhava firmemente para o pesquisador, no momento em que o pesquisador apontava para uma das duas palavras - significava que aquele ítem era o ítem correto para TH.

Para a elaboração deste teste, variáveis como a frequiência e extensão dos itens foram consideradas. Para avaliar as respostas foram utilizadas a análise das respostas corretas e a análise dos erros.

\section{A Testes de leitura de pseudopalavras}

Para analisar as estratégias utilizadas pelo sujeito TH no domínio da ortografia da língua portuguesa, elaborou-se uma lista de 12 pares de pseudopalavras que diferenciavam 
MACEDO - Leitura e escrita na ausência da fala

apenas pela consoante inicial. Este teste tem por objetivo avaliar a capacidade de descodificação, teste este que teve a mesma forma de apresentação que o teste de discriminação de palavras escritas.

\section{A. Teste de ortografia}

Este teste teve como objetivo analisar os mecanismos ortográficos utilizados por TH. Foi proposto à TH e ao grupo controle uma lista de 12 pares de palavras que diferenciavam apenas pela representação gráfica. $\mathrm{O}$ sujeito, lendo os pares de palavras, deveria fazer o reconhecimento da representação ortográfica de uma palavra quando esta tinha de ser distinguida de uma pseudopalavra homófona. Por exemplo: entre os pares de palavras Casa e Caza, o sujeito deveria marcar na folha resposta Casa. No caso de TH, o experimentador mostrava a palavra Casa e perguntava: "esta palavra está correta?". Depois o experimentador mostrava a outra palavra Caza e perguntava: "esta palavra está correta?". TH respondia olhando firme para o pesquisador, bastando para isto que lhe fosse apontada a resposta que ele achasse correta.

Entre os grafemas selecionados estavam apenas os de correspondência biunívoca. $\mathrm{O}$ quadro dos grafemas foi o seguinte; /z/ /s/ - /ch//x/ - /j/ /g/ / /ç//ss/ -/s//c/-/x//s/.

\section{Resultados do experimento 1}

Alguns estudos já evidenciaram as dificuldades que indivíduos com paralisia cerebral e anártricos, como é o caso de TH, deixaram transparecer quando adquiriram as habilidades de letramento. Normalmente, estas crianças apresentavam prejuízos na aprendizagem da leitura e da escrita porque demonstravam déficit na análise segmentar das palavras, provavelmente em função de dificuldades em tomar consciência da estrutura fonêmica da fala, o que coloca obstáculos para o domínio dos princípios alfabéticos. Surpreendentemente, apesar de TH ter tido Anoxia, com seqüelas motoras graves (tetraplesia) e ausência da fala produtiva, limitando, consequentemente, o seu contato com o mundo, os resultados dos testes podem nos levar a supor que TH lê e escreve, ou seja, ele identifica palavras, associa uma combinação particular de letras a um sentido correspondente.

Volta-se a citar o caso de Richard Boydell estudado por Fourcin (1975), por se similar ao caso de TH. Boydell era um sujeito quadriplégico congênito, anártrico e com perda de audição de alta freqüencia mas que tinha uma boa compreensão da língua oral, lia e escrevia. Fourcin (1975) afirmava que as capacidades expressivas podem ser desenvolvidas subclinicamente, de tal forma que pessoas anátricas tendo tido compreensão passiva, possam se engajar ativamente em interação verbal através de um mediador. Com Richard Boydell também foi, principalmente, com a ajuda e trabalho resignado de sua mãe que ele entrou em contato com a linguagem falada, leitura e escrita. Portanto, pode-se dizer que estes casos são semelhantes em alguns pontos mas bastante diferentes no que diz respeito à escolarização pois enquanto TH freqüenta uma escola pública da rede normal de ensino, Richard Boydell não teve educação formal, foi alfabetizado em casa por sua mãe. Boydell era capaz de escrever sozinho fazendo uso de um "foot-controlled typewriter" já TH precisa 
de um mediador até mesmo para utilizar o seu computador - Mac - pois, necessita de que uma outra pessoa não só posicione o mouse em cima de uma dada fila de letras, em uma dada letra, mas também que o coloque entre o encosto da cadeira de rodas e suas costas para que ele possa fazer a sua escolha, pressionando as costas para trás.

A aprendizagem de um sistema alfabético implica em descobrir a percepção que o indivíduo tem da cadeia da fala como um contínuo. Certamente, TH e Boydell, quando começaram a ler e escrever, no sistema alfabético, tiveram que fazer uma reeducação da fala - que eles nunca possuíram - tiveram que se debruçar sobre a compreensão da língua oral para perceber como os sons da fala eram pronunciados para, finalmente, desmembrar essa cadeia da fala em partes menores que a sílaba e internalizar as regras de correspondência grafema-fonema. Se, por um lado, para eles aprenderem a ler em um sistema alfabético tiveram que ser capazes de manipular os segmentos fonéticos da língua por outro, para manipularem os segmentos fonéticos da língua tiveram que aprender a ler um sistema alfabético. Muitos estudos mostraram que as habilidades metafonológicas envolvidas no processamento da escrita (alguns dos quais serão estudados no experimento 2) estão fortemente relacionadas aos desempenhos de leitura.

Supõem-se através das respostas do teste de reconhecimento de palavras para leitura que TH mantém relativamente intacta a via grafo-fonologica uma vez que acertou todas as 12 palavras que lhe foram apresentadas. No grupo controle dos 14 sujeitos 13 sujeitos acertaram todas as palavras apresentadas e um único sujeito (9) acertou somente $50 \%$ das palavras apresentadas. Portanto, pode-se dizer que TH tem capacidade para identificar palavras e capacidade para compreender a fala.

No teste de escrita foram apresentadas palavras com grafias diferentes, mas com o mesmo som. Este teste implicou não só um conhecimento morfológico mas, também, um conhecimento de ordem fonológica. Portanto, pode-se inferir que TH não apresentou dificuldades em aceder ao léxico semântico uma vez que acertou 91,67\%. O grupo controle teve um índice de acerto de $83,33 \%$ com um desvio padrão de $23,57 \%$, demonstrando que TH teve um desempenho normal em comparação ao grupo.

A palavra que TH errou a grafia com / x / ou / s / foi aquela que somente 42,85\% dos sujeitos do grupo controle acertaram, palavra com menor índice de acerto, depois vieram as grafias / z / e / s / com 50\% de acerto, / j/ e / g / com 78,57\% e / x / e / ch / com 85,71\% de acertos. Os demais grafemas /ç/ e /ss/ - /s/ - /c/ tiveram 92,85\% de acerto.

No teste de leitura de pseudopalavras onde se fez necessária a construção da leitura a partir do som, TH entre as 12 pseudopalavras apresentadas, acertou 11 ou média de 91,67\% de acertos. No grupo controle, o índice de acertos foi de 95,24\% de acertos com desvio padrão de $6,07 \%$ de desvio padrão repetindo um desempenho normal do sujeito pesquisado. TH não distinguiu a realização dos fonemas / b / e / d / da mesma forma que 6 sujeitos do grupo controle não distinguiram; um sujeito não distinguiu entre os pares de fonemas / p / e / v / e um outro sujeito não distinguiu entre os pares de fonemas / p / e / d /. Pode-se supor que os sujeitos falharam nesta distinção porque os fonemas / b / e / d / só diferem quanto ao ponto de articulação (e escrita semelhante), enquanto os fonemas / p/ e / v / diferem tanto no modo quanto no ponto de articulação e os fonemas / p / e / d /, apesar de serem oclusivas, diferem no modo e no ponto de articulação. 
Neste teste foi preciso que TH observasse e identificasse a composição da palavra apresentada. Pois, as pseudopalavras são itens que obedecem ao sistema fonológico de uma dada língua, sem contudo fazerem parte de seu léxico. Desta forma, as pseudopalavras não podem ser identificadas diretamente. O leitor é obrigado a criar uma representação fonológica e com ela acessar o léxico. Portanto, para ler uma pseudopalavra é preciso, obrigatoriamente, passar pela aplicação de regras da transformação grafema-fonema. Logo, TH utilizou os seus conhecimentos grafo-fonológicos e formou uma representação de uma palavra desconhecida.

\section{Experimento 2}

\section{Avaliação das habilidades metalingüísticas}

O objetivo da avaliação das habilidades metalingüísticas é de procurar relacionar as deficiências na leitura e na escrita a déficits particulares das habilidades que compõem tais capacidades.

Todos os três testes que compõem essa bateria foram realizados em duas etapas. A primeira foi realizada em 15-04-99 e a segunda em 13-06-00.A diferença entre as etapas se encontra no teste de discriminação perceptiva. Na primeira etapa a lista era composta de 32 pares de palavras. A segunda etapa continha 56 pares de palavras. O propósito de se repetir o teste com o aumento de pares de palavras, que se diferenciavam apenas por um grafema, foi o de observar se as respostas de TH eram recorrentes. Ao grupo controle, esta bateria de testes foi aplicada somente uma vez, ou seja, igual ao último experimento a que TH foi submetido.

\section{B. Habilidades de percepção da fala e memória de trabalho fonológica}

Com o objetivo de avaliar como interagem as habilidades de segmentação, percepção fina da fala e memória de trabalho fonológica, o seguinte teste foi apresentado a TH e ao grupo controle em duas fases diferentes.

Na primeira fase (15.04.99), elaborou-se uma lista de 32 pares de palavras e na segunda fase (13.06.00), uma lista de 56 pares de palavras que diferiam apenas por um grafema que poderia estar em posição inicial, intermediária ou final. Os pares de palavras tinham a estrutura CV e CCV, variando a extensão (1 a 2 sílabas). Neste teste os sujeitos ouviam duas palavras que poderiam ser as mesmas ou não e a tarefa consistia em dizer se elas eram iguais ou diferentes.

As respostas seriam medidas em termos de porcentagem de respostas corretas.

\section{B. Habilidades Metafonológicas}

A habilidade metafonológica objetivava, fundamentalmente, avaliar a competência dos sujeitos em relação à segmentação da fala. 


\section{B.1.Tarefa de inversão silábica e fonêmica}

A tarefa de inversão silábica e fonêmica tinha por objetivo avaliar as habilidades de manipular estas estruturas em dificuldades crescentes.

Este teste foi composto por três partes: a) inversão fonêmica $\mathrm{VV}$ - contendo 2 itens; b) inversão fonêmica CV - VC - contendo 2 itens de cada ; c) inversão silábica VCV contendo 4 itens.

\section{B Tarefa de acrônimos auditivos}

Os acrônimos auditivos são pares de palavras apresentados auditivamente. Nesta tarefa foram apresentado 8 pares de palavras na primeira parte do teste e 8 palavras na segunda parte do teste. A tarefa do sujeito consistia em separar o fonema inicial das duas palavras dadas para, reunindo-as, formar nova palavra.

Com o mesmo objetivo, este teste foi apresentado de duas formas diferentes. Na primeira parte do teste, os sujeitos ouvindo os pares de palavras, deveriam escolher a resposta correta entre respostas fonológicas e ortográficas. Na segunda parte do teste, além das respostas fonológicas e ortográficas, havia uma terceira escolha um distrator.

O teste foi concebido de forma a possibilitar dois tipos de respostas: nível da representação fonológica (resposta correta) e nível da representação ortográfica (indica que para separar o fonema inicial das duas palavras dadas e reuni-las é necessário passar pela representação ortográfica).

Resultados do experimento 2

$\mathrm{O}$ teste estudos das capacidades perceptivas avaliou como interagem as habilidades de segmentação, percepção fina da fala e memória de trabalho fonológica de TH. As respostas deste teste foram medidas em termos de porcentagem de respostas corretas.

\begin{tabular}{|c|c|c|}
\hline $\begin{array}{c}\text { Estudo das capacidades de } \\
\text { discriminação perceptiva }\end{array}$ & Pares de palavras iguais & Pares de palavras diferentes \\
\hline $\begin{array}{c}\text { Média de acertos de TH - em } \\
15.04 .99\end{array}$ & $93,75 \%$ & $81,25 \%$ \\
\hline $\begin{array}{c}\text { Média de acertos de TH - em } \\
13.06 .00\end{array}$ & $100 \%$ & $85,71 \%$ \\
\hline $\begin{array}{c}\text { Média de acertos do Grupo } \\
\text { Controle }\end{array}$ & $88,93 \%$ & $89,93 \%$ \\
\hline $\begin{array}{c}\text { Desvio Padrão do Grupo } \\
\text { Controle }\end{array}$ & $10,96 \%$ & $11,69 \%$ \\
\hline
\end{tabular}


No teste de discriminação perceptiva para pares de palavras iguais, TH apresentou um desempenho, na primeira vez, de $93,75 \%$ enquanto, na segunda vez, de $100 \%$. Já o grupo controle apresentou uma média de $88,93 \%$ com um desvio padrão de $10,96 \%$. Para o teste de discriminação perceptiva para pares de palavras diferentes, TH teve um acerto de $85,71 \%$ enquanto a média de seus colegas foi de $89,93 \%$ com desvio padrão de $11,69 \%$, evidenciando um desempenho normal, apenas um desvio padrão em torno da média. Portanto, para responder a este teste, TH segmentou a informação acústica em unidades fonológicas, reconheceu estas unidades e analisou, intencionalmente, estas unidades de forma normal em comparação ao grupo controle.

Os resultados dos testes indicam que as vogais foram mais fáceis de assimilar do que as consoantes, ou porque puderam funcionar como sílabas e ou porque puderam ser pronunciadas sozinhas. As consoantes oclusivas $[b, d, g, p, t, k]$ foram os segmentos mais difíceis de assimilar, pois são as consoantes mais sensíveis no contexto vocálico em que aparecem, o reconhecimento das consoantes está na dependência de seu contexto vocálico imediato. É o chamado fenômeno da coarticulação. A vogal condiciona o gesto fonoarticulatório. As dificuldades que os sujeitos tiveram com as letras b, p, d, q, g, não vêm de problemas viso-espaciais (CONTENT, 1984; CONTENT, KOLINSKY \& MORAIS, 1984). Acredita-se que as principais dificuldades ocorreram porque as oclusivas apresentam sons mais difíceis de serem assimilados acusticamente. Por exemplo: $\mathrm{P}$ - acusticamente é mais próximos de $\mathrm{B}$ e $\mathrm{T}$ - que acusticamente são mais próximos de $\mathrm{D}$ e $\mathrm{K}$ - que acusticamente é mais próximo de G. Finalmente, também as representações ortográficas têm uma aparência semelhante.

Em resumo, o exame dos processos implícitos na leitura conduzem à idéia de que as dificuldades encontradas para se aprender a ler e a escrever não são de natureza perceptiva, pois, para uma criança aprender a ler no sistema alfabético tem que analisar a língua, tendo consciência da sua estrutura fonética.

O teste de inversão silábica e fonêmica $(\mathrm{me}=\mathrm{m}-\mathrm{e}=\mathrm{e}-\mathrm{m})$ testou se os sujeitos já teriam internalizados um dos princípios do sistema alfabético do português do Brasil que, de acordo com Scliar-Cabral (1999a), conforme a posição que o vocábulo escrito ocupa pode representar um som diferente, ou seja, o som [m], em início de sílaba, ou pode nasalizar a vogal antecedente, em posição final de sílaba interna do vocábulo, ou além de nalisalizar, ditongar a vogal precedente, em final de vocábulo.

Os resultados dos testes de inversão silábica e fonêmica demonstraram que TH teve, na primeira fase, $60,00 \%$ de acerto e, na segunda fase, teve 50,00\% de acerto, ficando abaixo da média de acerto do grupo controle $75,71 \%$, porém, considerando o desvio padrão elevado do grupo $33,32 \%$, pode-se considerar que o sujeito $\mathrm{TH}$ ainda apresentou um desempenho normal já que se situa a menos de 1 desvio padrão do grupo controle tanto no primeiro quanto no segundo teste.

Os dados sugerem que TH teve mais dificuldades que o grupo controle em associar os grafemas aos fonemas correspondentes conforme a posição que o vocábulo ocupava. A dificuldade de realizar esta tarefa pode ter vindo do fato de que ela não possibilitava a comparação dos itens apresentados a outros análogos nem a informações contextuais. Para realizar esta tarefa foi preciso que o sujeito, ouvindo os fonemas e as sílabas, fizesse a inversão mentalmente e soubesse como eles deveriam ser pronunciados. 
Observou-se, a partir dos resultados do teste de inversão silábica e fonêmica, que, ao contrário de $\mathrm{C}$, a parte $\mathrm{V}$ não pode faltar nem figurar duas vezes na mesma sílaba.

A tarefa de acrônimos auditivos foi composta por 16 pares de palavras apresentados auditivamente. Nessa tarefa os sujeitos deveriam separar o fonema inicial das duas palavras dadas e as reunir, formando uma nova palavra.

Na primeira fase do teste, os sujeitos puderam escolher entre dois tipos de respostas: nível da representação fonológica e nível da representação ortográfica. Os resultados dos testes demonstraram que TH teve, em 15.04.99, 87,5\% de acertos e, em 13/06/00, 75,00\% de acerto já o grupo controle apresentou $96,43 \%$ de acerto com desvio padrão de $12,88 \%$. Assim, no teste de 13/06/00, pela primeira vez, o sujeito TH teve um número de acertos fora da zona de 1 desvio padrão em torno da média ou seja neste teste ele estaria com 2 desvios padrões em torno da média, já no teste de 15/04/00 ele estava a menos de um desvio padrão da média.

Na segunda fase do teste, os sujeitos puderam escolher entre três tipos de respostas: nível da representação fonológica, nível da representação ortográfica e um ítem distrator.

Os resultados da segunda fase dos testes demonstraram que TH teve, em 15/04/99, $37,50 \%$ de respostas fonológicas, 37,50\% de respostas ortográficas e 25,00\% de respostas no item distrator. Em 13/06/00, TH aumentou as suas respostas fonológicas para 50,00\%, permaneceu com 37,50\% de respostas ortográficas e diminuiu as suas respostas no item distrator $12,50 \%$. O grupo controle apresentou 30,36\% de respostas fonológicas com um desvio padrão de $34,95 \%, 67,86 \%$ de respostas ortográficas com desvio padrão de $34,95 \%$ e $1,79 \%$ de respostas no item distrator com desvio padrão de $4,37 \%$.

Conforme explicado anteriormente, neste teste foi considerada resposta correta a resposta fonológica. E, a partir dos resultados abaixo, pode-se observar que TH obteve a maior porcentagem de respostas fonológicas $37,5 \%$ e $50,00 \%$, consideradas respostas corretas, contra $30,36 \%$ do grupo controle.

As respostas dos sujeitos do grupo controle revelaram que 50,00\% dos sujeitos apresentaram comportamentos bem definidos, ou seja, 35,71\% tiveram somente respostas ortográficas, $14,28 \%$ tiveram somente respostas fonológicas e os outros $50,00 \%$ dos sujeitos variaram entre respostas fonológicas, ortográficas e o item distrator.

\begin{tabular}{|c|c|c|c|c|}
\hline Respostas & Média TH - 15/04/99 & Média TH - 13/06/00 & Média - grupo controle & Desvio padrão - grupo controle \\
\hline Fonológicas & $37,50 \%$ & $50,00 \%$ & $30,36 \%$ & $34,95 \%$ \\
\hline Ortográficas & $37,50 \%$ & $37,00 \%$ & $67,86 \%$ & $34,95 \%$ \\
\hline Distrator & $25,00 \%$ & $12,50 \%$ & $1,79 \%$ & $4,37 \%$ \\
\hline
\end{tabular}

A idéia que se quis manifestar nestes testes foi de que é indispensável tomar consciência do fonema e da sílaba para se adquirir o código alfabético e, conseqüentemente, ler bem. 


\section{CONCLUSÕES FINAIS}

Estudos demonstraram que crianças portadoras de anomalias severas na produção da fala não desenvolvem um conhecimento apropriado das estruturas das palavras. Não tendo desenvolvido competências morfofonêmicas, estas crianças apresentam dificuldades para aquisição do conhecimento das regras de correspondência grafo-fonologica. Contrariando estes estudos, os resultados dos experimentos 1 e 2 sugerem que TH, sujeito com comprometimento motor e anártrico, apresenta as habilidades de compreensão oral, leitura e escrita com desempenho ora superior, ora inferior ao grupo controle sem contudo apresentar diferenças de desempenho anormais ao grupo. Considerando-se que, na grande maioria dos testes, o desempenho de TH está a menos de um desvio padrão em torno da média, rejeita-se a hipótese básica de que sujeitos que não falam não deveriam ler e escrever. TH lê e escreve normalmente como seus colegas de série.

Assim, pode-se demonstrar que todo ser humano tem que ser levado a descobrir a estrutura fonética da língua. Ele precisa de uma intervenção externa e esta intervenção é geralmente o fato dele ter que aprender a ler em um sistema alfabético (ALEGRIA \& MORAIS, 1979). Logo, as habilidades de leitura e escrita precisam ser adquiridas e é a partir da descoberta dos princípios alfabéticos que o indivíduo poderá utilizá-los em novas relações de grafemas e fonemas. Esta nova habilidade supõe, ainda, a capacidade de memorização das correspondências encontradas e a capacidade de análise e síntese para se reutilizar na leitura de outras novas palavras (MORAIS, 1996).

A partir dos resultados destes experimentos, pode-se constatar que alguns indivíduos não falantes com paralisia cerebral por causa de seu dano motor, precisam não de um treinamento especial para desenvolver as habilidades de leitura e escrita, mas de um mediador afetuoso, motivador e hábil que torne possível a esse indivíduos o contato com a leitura e a escrita. Ou, ainda dizendo, de um mediador que desenvolva o contato destes indivíduos com o mundo a sua volta. Que possibilite a esses indivíduos não somente a comunicação com outras pessoas, mas também informações através do rádio, televisão, literatura, teatro e porque não da escola?

TH estuda em uma escola da rede pública e, por isto, não recebeu um tratamento diferenciado dos colegas de sala de aula para o desenvolvimento de habilidades tais como análise de padrão de som, conhecimento de vocabulário, compreensão de sintaxe e discurso, habilidades que estão possivelmente relacionadas a um bom desenvolvimento de alfabetização entre crianças falantes. Simplesmente, TH teve o apoio da sua família e de uma escola que o acolheu, dando-lhe oportunidades para que aprendesse o sistema alfabético de forma consciente. Portanto, a consciência fonêmica é uma condição central na aquisição da escrita alfabética, pois além de estar ligada diretamente à aquisição do princípio alfabético, mostra-se como uma importante capacidade para o sucesso na leitura e na escrita.

Se, por um lado, a aprendizagem do sistema alfabético de TH e de seus colegas dependeu de um ensino sistemático, intensivo e da necessidade de ler e escrever; por outro lado, TH e seus colegas só aprenderam a ler e escrever porque foram capazes de manipular os segmentos fonéticos da língua. Portanto, pode-se dizer que TH não tem somente capacidade para identificar palavras, ler e escrever, mas também tem capacidade para compreender a fala. 


\section{REFERÊNCIAS BIBLIOGRÁFICAS}

ABAURRE, M. B. M. (1998). Dados da escrita inicial: indícios de construção da hierarquia de constituintes silábicos? V Congresso Brasileiro de Lingüística Aplicada - Porto Alegre, UFRGS/ALAB.

ALEGRÍA et al. (1997). Aquisição da leitura e distúrbios associados: avaliação, tratamento e teoria. It: Grégoire, J. \& Piérart, B. (Orgs.) - Avaliação dos problemas de leitura: os novos modelos teóricos e suas implicações diagnosticas, Porto Alegre: Artes Médicas.

ALEGRIA, J. (1985). Por un enfoque psicolingüístico del aprendizaje de lectura y sus dificultades. Infancia y Aprendizaje, 29: 79-94.

ALEGRIA, J., \& MORAIS, J. (1979). Le developpement de l'habilité d'analyse consciente de la parole et l'apprentissage de la lecture. Archives de Psychologie, 183: 251-270.

BADDELEY A., \& WILSON, B. (1985). Phonological coding and short-term memory in patients without speech. Journal of Memory and Language, 24: 490-502.

BAST, J. (1995). The development of0 individual differences in reading ability. Amsterdam/Duivendrecht: Paedologisch Institut.

BERNINGER, V., \& GANS, B.M. (1986a). Language profiles in nonspeaking individuals of normal intelligence with severe cerebral palsy. Augmentative and Alternative Communication, 2: 45-50.

BERTELSON, P. (1987). The onset of literacy: Cognitive processes in reading acqisition. Cambridge: MIT Press edition.

BISHOP, D.V.M. (1985). Spelling ability in congenital dysarthria: evidence against articulatory coding in translating between grafemes and phonemes. Cognitive Neuropsychology, 2: 229-251.

BISHOP, D.V.M., \& ADAMS, C. (1990). A prospective study of de relationship between specific language impairment, phonological disorders and readind retardation. Journal of Child Psychology and Psychiatry, 31: $1027-1050$.

BISHOP, D.V.M., \& ROBSON, J. (1989). Accurate non-word spelling despite congenital inability to speak: phoneme-grapheme conversion does not require subvocal articulation. British Journal of Psychology, 80: $1027-1050$.

BISHOP, D.V.M., BYERS B.B., \& ROBSON, J. (1990). The relationhip between phoneme discrimination, speech production and language comprehension in cerebral-palsied individuals. Jounal of Speech and Hearing Research, 33: 210-219.

BRADY, S., FOWLER, A., STONE, B., \& WINBURG, N. (1994). Training phonological awareness: A study with inner-city kindergarten children. Annals of Dyslexia, 44: 26-59.

BRUCK, M. (1992). Persistence of dyslexics phonological awareness deficits. Development Psychology, 28: $874-886$.

BYRNE, B., \& FIELDING-BARNSLEY, R. (1993). Evaluation of a program to teach phonemic awareness to young children: A 1-year follow up. Journal of Educational Psychology, 85: 104 - 111.

(1995). Evaluation of a program to teach phonemic awareness to young children: A 2-year follow-up and a new preschool trial. Jouranal of Educational Psychology, 87: 488-503. 
CONTENT, A. (1984). L'habilité d'analyse phonétique et l'acquisition de la lecture. L'Année Psychologique, en prense.

DAHLGREN S.A., \& HJELMQUIST, E. (1996a). A comparative, descriptive study of readind and writing skills among nonspeaking chidren. A preliminary study. European Journal of disrders of Communication, 31: 289-308.

. (1996b). Phonological awareness and literacy abilities in nonspeaking preschool chidren with cerebral palsy. Augmentative and Alternative Communication, 12: 138-153.

DODD, B., LEAHY, J. \& HAMBLY, G. (1989). Phonological disorders in children: Underlying cognitive deficits. British Journal of Developmental Psychology, 7,55-71.

EDEBOL-TYSK. (1989). Spastic Tetraplegic Cerebral Palsy, epidemiology and Care Load. Doctoral thesis. Göteborg University: Department of Paediatrics II.

ELLIS, N. (1990). Reading, phonological skills and short-term memory: Interactive tributaires of development. Journal of Research in reading, 13: 107-122.

FOLEY, B.E. (1993). The development of literacy in individuals with severe congenital speech and motor impairments. Topics in Language Disorders, 13: 16-32.

FOURCIN, A.J. (1975). Language development in the absence of expressive speech. Foundations of Language Development. A multidisciplinary approach. 2: 263-267.

GATHERCOLE, S.E., \& BADDELEY, A.D. (1990). Phonological memory deficits in language disordered children: Is there a causual connection? Journal of memory and language, 29: 336-360.

GATHERCOLE, S.E., WILLIS, C., \& BADDELEY,A.D. (1991). Differentiating phonological memory and awareness of rhyme: Reading and vocabulary development in children. British Journal of Psychology, 82: $387-406$.

GOLDSTEIN, D.M. (1976). Cognitive-linguistic funcioning and learning to read in preschoolers. Journal of Educational Psychology, 68: 680-688.

GOSWAMI, U., \& BRYANT, P.(1990). Phonological skills and learning to read. Hillsdale, NJ: Lawrence Erlbaum Associates. London.

HEDELIN, L., \& HJELMQUIST, E. (1988). Preschool children's mastery of the form/content distinction in spoke language. In: Ekberg, K. e Mjaavatn, P.E. (Eds.). Growing into a modern world. The Norwegian Centre for Chil Research, The University of Trondheim. 639-645.

HEHNER, B. (1982). Blissymbols for use. Toronto: Blissymbolics Communication Institute.

HOIEN, T., \& LUNDBERG, I. (1992). Dyslexi [Dyslexia]. Stockholm: Natur och Kultur.

KELFORD, S.A ., THURSTON, S., LIGHT, J., PARNES, P., \& O'KEEFE, B. (1989). The form and use of written communication produced by nonspeaking physically disabled individual using microcomputers. Augmentative and Alternative Communication, 5: 115-124.

KOKE, S., \& NEILSON, J. (1987). The effect of auditory feedback on the spelling of non-speaking physically disabled patients. Unpublished Masters thesis. Toronto: University of Toronto.

KOPPENHAVER, D.A., EVANS, D.A., \& YODER, D.E. (1991). Childhood reading and writing experiences of literate adults with severe speech and motor impairments. Augmentative and Alternative Communication, 7: $20-33$. 
LUNDBERG, I. (1989). Lack of phonological awareness - a critical factor in dyslexia. In: C von Euler, Lundberg, I. Lennerstrand, G. (eds). Brain and Reading. London: Macmillan, 221-231.

(1991). Reading as an individual and social skill. In: Lundberg, I. T Hoien (eds). Literacy in a World of Change - perspective on Reading and Reading Disability. Stavanger: Centre for Reading Research, $14-22$.

LUNDBERG, I., FROST, J., \& PETERSEN, O. (1988). Effects of na extensive program for stimulating phonological awareness in preschool children. Reading Reasearch Quartely, 23: 263-284.

MANN, V.A., \& DITUNNO, P. (1990). Phonological deficiencies: Effective predictors of future reading problems. In: Paavlidis, G. (Ed.). Perspectives on dyslexia, 2: 105-131. New York: Wiley.

MATTINGLY, I. G. (1972). Reading, the linguistic process, and linguistic awareness. In: J. F. Kavanagh \& I. G. Mattingly (Eds.). Language by ear and by eye, Cambridge, MA: MIT Press.133-147.

MCGINNIS, J.S., \& BEUKELMAN, D.R. (1989). Vocabulary requirements for writing activities for the academically mainstream stdent with disabilities. Augmentative and Alternative Communication, 5: 183 191.

MORAIS, J. ALEGRÍA, J., \& CONTENT, A. (1987). The relationship between segmental analysis and alphabetic literacy: Na interactive view. Cahiers de Psychologie Cognitive, 7: 415-438.

MORAIS, J. (1994). Reasons to pursue the study of phonological awareness. Readind and Writing: An Interdisciplinary Jounal, 6: 219-220.

MORAIS, J., \& ROBILLARD, G. (1998). Apprendre à lire - au cycle des apprentissages fondamentaux Analyses, réflexions et propositions. Editions Éditions Odile Jacob.

MORAIS, J., MOUSTY, P., \& KOLINSKY, R. (1998). Why and how phoneme awareness helps learning to read. In: Hulme, C. \& Joshi, R. M. Reading and spelling: development and disorders. Mahwah, N. J., Lawrence Erlbaum, 127-151.

MOUSTY, P., LEYBAERT, J., ALEGRÍA, J., CONTENT, A., \& MORAIS, J. (1998). Belec: uma bateria de avaliação da linguagem escrita e de seus distúrbios. It: Grégoire \& Piérart - op.cit.

NAKAMURA, M., KOLINSKY, R., SPAGNOLETTI, C., \& MORAIS, J. (1998). Phonemic awareness in alphabetically literate japanese adults: the influence of the first acquired writing system. Cahiers de Psychologie Cognitive/Current Psychology of Cognition, 17 (2): 417-450.

NÄSLUND, J.C., \& SCHNEIDER, W. (1996). Kindergarten letter knowledge, phonological skills, and memory processes: Relative effects on early literacy. Journal of Experimental Child Psychology, 62: 30-59.

OLSON, D.R. (1982). What is said and what is meant in speech and writing. Visible Language, 16: 151-161.

RANKIN, J.L., HARWOOD, K., \& MIRANDA, P. (1994). Influence of graphic symbol use on reading comprehension. Augmentative and Alternative Communication, 10: 269-281.

ROTH, F.P., \& CASSAT-JAMES, E.L. (1898). The language assessment process: Clinical implications for individuals with severe speech impairments. Augmentative and Alternative Communication, 5: 165172.

SANDBERG, A.D., \& HJELMQUIST, E. A. (1996). Comparative, descriptive study of reading and writing skills among non-speaking children: a preliminary study. European Jounal of Disorders of Communications, 31: 289-308. 
MACEDO - Leitura e escrita na ausência da fala

SANDBERG, A.D., \& HJELMQUIST, E. A. (1997). Language and literacy in nonvocal children with cerebral palsy. Interdisciplinary Jounal, 9: 107-133.

SCLIAR-CABRAL, L. (2003). - Princípios do Sistema Alfabético do Português do Brasil. . (1999b). Effects of literacy on metalinguistic awareness, Cahiers d'aquisition \& pathologie du langage

SMITH, M.M. (1992). Reading abilities of nonspeaking students: two case studies. Augmentative and Alternative Communication, 8: 57-66.

. (1989). Reading without speech: a study of children with cerebral palsy. The Irish Journal of Psychology, 10: 601-614.

SNOWLING, M.J. (1991). Developmental reading disorders. Journal of Child psychology and Psychiatry, 32: 49-77.

STANOVICH, K. (1986). Matthhew effects in reading: Some consequences of individual differences in the acquisition of literacy. Readind Research Quarterly, 21: 336-407.

WAGNER, R.K., \& TORGESEN, J.K. (1987). The nature of phonological processing and its causal role in the acquisition of reading skills. Psychological Bulletin, 101: 192-212.

WAGNER, R.K., TORGESEN, J. K., RASHOTTE, C.A., HECHT, S. A., BARKER, T.A., BURGESS, S.R., DONAHUE, J., \& GARON, T. (1997). Changing relations between phonological processing abilities and word-level reading as children develop from beginning to skilled readers: A 5-year longitudinal study. Developmental Psychology, 33: 468-479.

WAGNER, R.K., TORGESEN, J.K., \& RASHOTTE, C.A. (1994). Development of readind-related phonological processing abilities: New evidence of bidirectional causality from a latent variable longitudinal study. Developmental Psychology, 30: 73-87.

WIMMER, H., LANDERL, K., LINORTNER, R., \& HUMMER, P. (1991). The relationship of phonemic awareness to reading acquisition: More consequence than prediction but still important. Cognition, 40: 219-249. 